\title{
Technology to Detect Anomalies of Net Primary Production of Vegetation Dynamics on the Basis of Non-Linear Trends (MODIS NPP)
}

\author{
Aleksander A. Larko, \\ Julia D. Ivanova* and Anatoly P. Shevyrnogov \\ Institute of Biophysics $S B R A S$, \\ Federal Research Center "Krasnoyarsk Science Center SB RAS" \\ 50/50 Akademgorodok, Krasnoyarsk, 660036, Russia
}

The paper proposes a technology to detect anomalies of net primary production of vegetation dynamics and the authors have done an analysis of the data. The authors are based on ecological theory for conceptual technology that allows you to monitor an extended territory, using estimates NPP (MODIS NPP) as an indicator of the conditions of vegetation. For the detection of areas with anomalies NPP dynamics was used STL method (Seasonal-Trend Decomposition Procedure Based on Loess). The study was conducted in the south of the Krasnoyarsk region, which has a great variety of natural landscapes from the steppes to the high alpine meadows of the Sayan Mountains. For analysis of the dynamics of anomalies of NPP used satellite data in temperature and humidity.

Keywords: NPP, nonlinear trends, vegetation dynamics, satellite data.

Citation: Larko A.A., Ivanova Ju.D., Shevyrnogov A.P. Technology to Detect Anomalies of Net Primary Production of Vegetation Dynamics on the Basis of Non-Linear Trends (MODIS NPP), J. Sib. Fed. Univ. Eng. technol., 2017, 10(1), 113-125. DOI: 10.17516/1999-494X-2017-10-1-113-125.

(c) Siberian Federal University. All rights reserved

* Corresponding author E-mail address: lantar@inbox.ru, lulja@yandex.ru 


\title{
Технология обнаружения аномалий динамики \\ чистой первичной продукции растительности на основе нелинейных трендов (MODIS NPP)
}

\author{
А.А. Ларько, Ю.Д. Иванова, А.П. Шевырногов \\ Институт биофизики СО РАН \\ Федеральныий исследовательский центр \\ «Красноярский научный центр СО РАН» \\ Россия, 660036, Красноярск, Академгородок, 50/50
}

\begin{abstract}
В статье предложена технология обнаружения аномалий динамики чистой первичной продукции растительности и сделан анализ полученных данных. Авторы представляют основанную на экологической теории конщептуальную технологию, которая позволяет проводить мониторинг протяженной территории, используя оиенки ЧПП (MODIS NPP) в качестве индикатора состояния растительного покрова. Для обнаружения территорий с аномальной динамикой ЧПП использовался метод STL (Seasonal-Trend Decomposition Procedure Based on Loess). Исследование проводилось на территории юга Красноярского края, обладающего большим разнообразием природных ландшафтов - от степей до высокогорных альпийских лугов Саянских гор. Для анализа полученных аномалий динамики ЧПП использовались спутниковые данные по температуре и влажности.
\end{abstract}

Ключевые слова: ЧПП, нелинейные тренды, динамика растительности, спутниковые данные.

\section{Введение}

Чистая первичная продукция представляет собой количество углерода, ассимилированного зелеными растениями из атмосферы благодаря процессу фотосинтеза. Эта величина является одним из наиболее информативных показателей, который характеризует физиологическое состояние и продуктивность лесных экосистем. Динамика ЧПП зависит от влияния на лесные биомы факторов внешней среды и антропогенного воздействия. Чистая первичная продукция - показатель, позволяющий проследить изменения в растительных сообществах, в первую очередь изменения их продуктивности во времени на определенной территории. Таким образом, понимание основных механизмов, регулирующих процессы накопления и расхода углерода экосистемами, признано важнейшей основой для разработки рациональных стратегий лесохозяйственной деятельности и служит обоснованием системы мероприятий по смягчению нежелательных изменений в экосистемах средствами лесного хозяйства [1].

Значения ЧПП отличаются как для различных растительных биомов, так и для одинаковых растительных сообществ, произрастающих в разных природных условиях [2]. Основной сложностью при рассмотрении ЧПП выступает большая трудоемкость при определении его текущего значения как для отдельного растения (например, определенного дерева), так и для экосистемы в целом. В настоящее время используются оценки ЧПП на различных уровнях организации растительных сообществ - от методов, основанных на описании физиологических процессов в листовых пластинках [3], лесном пологе [4], ландшафтном уровне [5], регионе [6, 7], до описания процессов глобальной динамики роста растений $[8,9]$. 
Авторами рассматривается возможность использования оценок ЧПП (MODIS NPP) в качестве индикатора для проведения мониторинга состояния протяженных лесных массивов. Мы представляем основанную на экологической теории концептуальную технологию, которая позволяет использовать динамику ЧПП, зависящую от характеристик землепользования, лесопользования и изменений в растительном покрове, в качестве показателя мониторинга.

Согласно экологической теории ЧПП определяет величину продукции природных сообществ и является основой, приводящей в движение экологические процессы. Как правило, величина ЧПП на определенной территории зависит от произраставших на ней видов растений, и если видовой состав за рассмотренный период времени остается неизменным - значения ЧПП достаточно стабильны и меняются только в зависимости от погодных условий за вегетационный сезон. Что касается отдельных растений, значение ЧПП определяется состоянием листовых пластинок (листья, хвоя), в которых происходит процесс фотосинтеза, и, конечно, процессами дыхания растения. Если допустить, что на рассматриваемой территории не происходит значительных изменений в состоянии и видовом составе экосистемы, то значения ЧПП будут незначительно отклоняться от среднего. Напротив, если происходят изменения в видовом составе и состоянии растительности на рассмотренной территории - значения ЧПП будут изменяться либо резко (пожар, вырубки), либо постепенно в зависимости от характера повреждений (вспышки размножения вредителей-насекомых, усыхание и др.). Использование ЧПП в качестве индикатора состояния растительного покрова основано на свойстве ЧПП показывать состояние и состав растительности на подстилающей поверхности.

Основа предлагаемой технологии - построение нелинейных временных трендов значений ЧПП (MODIS NPP) в каждом пикселе наблюдаемой территории. В ряде работ рассматриваются линейные тренды $[10,11]$, однако нам представляется, что подход, основанный на линейных трендах, достаточно субъективен и его результат всецело зависит от выбора временного интервала. В большей части работ рассматриваются усредненные по площади динамические характеристики ЧПП или вегетационных индексов [12-14]. Полученные усредненные результаты при дальнейшей верификации их наземными данными зачастую очень неоднозначны.

Использование предлагаемой авторами технологии позволяет выделить проблемные участки на обширной территории и проанализировать причины происходящих процессов в растительном покрове на подстилающей поверхности, сузив площадь мониторинга в несколько десятков раз. В дальнейшем предполагается автоматизация этого процесса.

\section{Методы и данные}

В данной работе оценивались нелинейные тренды чистой первичной продукции растительности с 2000 по 2012 г. для юга Красноярского края (район бассейна реки Енисей). Общая площадь территории составляет 3000 км² (анализируемый участок размерностью 500 х 600 км). На данной территории находятся различные типы экосистем: степи Хакасии, лесостепи, хвойные и лиственные леса, горные территории Западного Саяна. Леса на территории района составляют 80 \% площади и приурочены к Саянам. На изучаемой горной территории представлены следующие высотные пояса: степной, лесостепной, черневой, таежный, субальпийский, альпийский. К основным сообществам относятся черневые леса - кедровники, пихтарники; таежные леса - кедровники, пихтарники, редколесья; кустарниковая растительность; тундры - 
кустарниковые, моховые и лишайниковые, луга - субальпийские и альпийские [15]. В результате исследования были построены нелинейные временные тренды ЧПП методом STL для различных растительных сообществ на данной территории, проанализированы их особенности и найдены территории с аномальной динамикой ЧПП.

Для оценки значений ЧПП на протяженных малодоступных территориях традиционно используются спутниковые данные [11, 16-18]. Расчет значений ЧПП основан на оптических спектральных данных и данных о подстилающей поверхности [19-21]. В данной работе для расчета ЧПП была использована модель MODIS NPP на основе данных MODIS/TERRA [22]. Главной особенностью этой модели является использование эмпирических зависимостей при расчете ЧПП для каждого из 15 наземных биомов планеты. При расчетах фитомассы, GPP (общая первичная продукция) и дыхания используется индекс площади листовой поверхности (LAI). Функции дыхания и GPP зависят от температуры. В дополнение к дыханию зеленой фитомассы учитывается дыхание стволов (при расчете среднегодовых значений ЧПП) и дыхание корней. Значения ЧПП были получены на основе данных сканера MODIS спутника Terra, в работе использовался продукт MOD17, пространственное разрешение 1 км². Временной ряд наблюдений с 2000 по 2012 г. Данные представляют собой композитные изображения, временной шаг 8 дней, рассчитанные на основе модели MODIS NPP.

Значения температуры подстилающей поверхности были получены на основе данных сканера MODIS спутника Terra, в работе использовался продукт MOD11, пространственное разрешение 1 км². Временной ряд наблюдений с 2000 по 2012 г. Данные представляют собой композитные изображения, временной шаг 8 дней, рассчитанные на основе данных 32 каналов сканера MODIS спутника Terra.

Влажность оценивается по индексу LSWI (Land Surface Water Index), который рассчитывается как нормализованная разница между $\mathrm{p}_{\text {nir }}\left(0,78-0,89\right.$ мкм) и $\mathrm{p}_{\mathrm{swir}}(1,58-1,75$ мкм) спектральными каналами спутника MODIS/Terra:

$$
L S W I=\frac{p_{\text {nir }}-p_{\text {swir }}}{p_{\text {nir }}+p_{\text {swir }}}
$$

Для декомпозиции временных рядов ЧПП, индекса влажности и радиационной температуры поверхности использовалась процедура сезонно трендовой декомпозиции, основанная на Лecce (Seasonal-Trend Decomposition Procedure Based on Loess - STL). Метод STL основан на фильтрации исходных данных для разложения сезонных временных рядов на три компоненты: сезонную, трендовую и остаточную (шум):

$$
\mathrm{D}_{\mathrm{i}}=\mathrm{T}_{\mathrm{i}}+\mathrm{S}_{\mathrm{i}}+\mathrm{N}_{\mathrm{i}}
$$

где $\mathrm{D}$ - значения временного ряда; T - трендовая составляющая ряда; $\mathrm{S}$ - сезонная составляющая ряда; $\mathrm{N}$ - остаточная составляющая ряда; $\mathrm{i}$ - шаг по времени.

Сущность метода состоит в последовательном применении к данным временного ряда Loess-сглаживаний [23]. Метод имеет свои особенности, сильные и слабые стороны. Например, метод STL в зависимости от заданной степени сглаживания способен выделять не только трендовые, но и тренд-циклические компоненты временных рядов. Эта дополнительная информация может послужить основой при анализе биологических и климатических причин 
таких колебаний динамики ЧПП различных экосистем, находящихся на изучаемой территории.

Особенностью используемого метода STL является то, что при увеличении размеров окна фильтрации происходит сглаживание кривой, которое приводит к вырождению нелинейного тренда в линейный. В результате этого могут быть потеряны важные особенности динамики ЧПП во времени, обусловленной внешними (температурно-влажностный режим, антропогенное воздействие и др.) или внутренними причинами (возраст, породный состав древостоя, другие характеристики растительного ценоза), оказывающими влияние на будущую динамику ЧПП. Следующим недостатком метода STL является тот факт, что при изменении длины временного ряда значения на концах полученных кривых заметно отличаются и могут наблюдаться существенные, зависимые от степени сглаживания, расхождения значений на концах полученных кривых. Таким образом, при использовании данного метода следует учитывать приведенные выше особенности [24].

\section{Результат}

Авторами предложена новая технология мониторинга обширных лесных массивов, основанная на построении и анализе нелинейных временных трендов сезонной динамики ЧПП. Общая схема предлагаемой технологии показана на рис. 1. На первом этапе выбирается период времени и рассматриваемая территория, которая может занимать площадь от нескольких квадратных километров до нескольких тысяч или десятков тысяч. Для построения нелинейных временных трендов ЧПП используется метод STL. Нелинейный временной ряд строится с необходимыми настройками метода в зависимости от поставленных задач мониторинга [24].

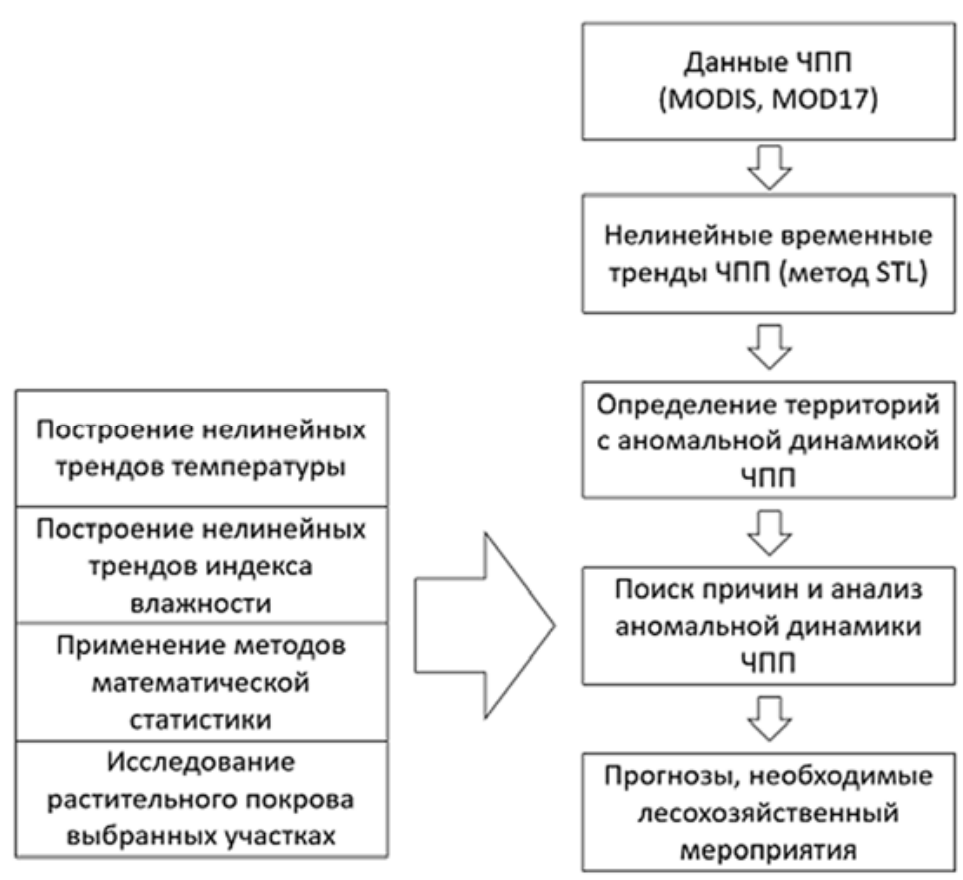

Рис. 1. Алгоритм предложенного метода обнаружения аномалий временной динамики ЧПП 
В результате применения метода нелинейный временной ряд ЧПП рассчитывается в каждом пикселе рассмотренной территории. В зависимости от динамики временного ряда данный пиксель территории попадает в разряд аномальных, если обнаруживается резкое изменение в динамике ЧПП. На данном этапе происходит выделение площадей с аномальной динамикой ЧПП на рассмотренной территории, и в дальнейшем продолжается работа только с выделенными территориями, что значительно сокращает объем вычислений.

Для анализа причин появления аномалий в динамике ЧПП дополнительно рассматриваются спутниковые данные по температуре и влажности (MODIS). На данном этапе строятся нелинейные временные тренды по данным температуры и влажности для выделенных территорий с аномальной динамикой ЧПП. В дальнейшем средствами статистического анализа отыскивается связь между временными рядами ЧПП и температурой или влажностью в каждом пикселе. Если аномалии в динамическом ряду ЧПП не связаны с погодными явлениями, переходим к анализу изменений в растительном покрове, которые могут быть связаны как с природными повреждениями (вспышки насекомых, пожары и др.), так и с антропогенным вмешательством (изменение землепользования, вырубки и др.). На основе проведенного анализа возможно построение прогнозов и выработка рекомендаций по лесопользованию на основе понимания причин появления территорий с аномальной динамикой ЧПП.

\section{Обсуждение}

C помощью метода STL были получены пространственно распределенные нелинейные тренды изменений чистой первичной продукции на территории юга Красноярского края. Пространственное распределение трендов ЧПП на рассмотренной территории показало особенности временной динамики значений ЧПП для различных растительных сообществ за 20002012 гг. Декомпозиция временных рядов ЧПП выявила аномальные зоны уменьшения, роста и стабильного поведения ЧПП на исследуемой территории за это время (рис. 2).

На рис. 2 показано, что зоны роста трендов ЧПП преимущественно соответствуют хвойным вечнозеленым лесам, зоны уменьшения расположены в смешанных и лиственных лесах, а стабильные значения присущи степным и сельскохозяйственным землям. При анализе временной динамики рядов ЧПП за период 2000-2012 гг. можно с уверенностью отметить общие изменения в значениях ЧПП на рассмотренной территории, произошедшие за тринадцать лет. Уменьшения значений ЧПП на данной территории произошли на равнинах и на территории предгорий Саян. Эти площади представляют собой либо сельхозугодия, либо луговую, лесную растительность, смешанную с сельхозугодиями на территориях, простирающихся вокруг p. Енисей и не достигающих высот 300 м над ур.м. Именно эти районы наиболее подвержены антропогенному воздействию, и именно они страдают в первую очередь при неблагоприятных погодных условиях, таких как засухи.

В основном на исследованной территории значения ЧПП остаются достаточно стабильными за период 2000-2012 гг. Эти территории заняты смешанными лесами с преобладанием лиственных пород и расположенных на высотах приблизительно до 500-600 м над ур.м. Положительная динамика ЧПП за рассмотренный период времени наблюдается только на территории, занятой хвойными видами деревьев. Это горные леса Западного Саяна на высотах 600-1200 м над ур.м. Данные территории не подвержены массированному антропогенному воздействию, 
А. Нелшнейные тренды ЧПП

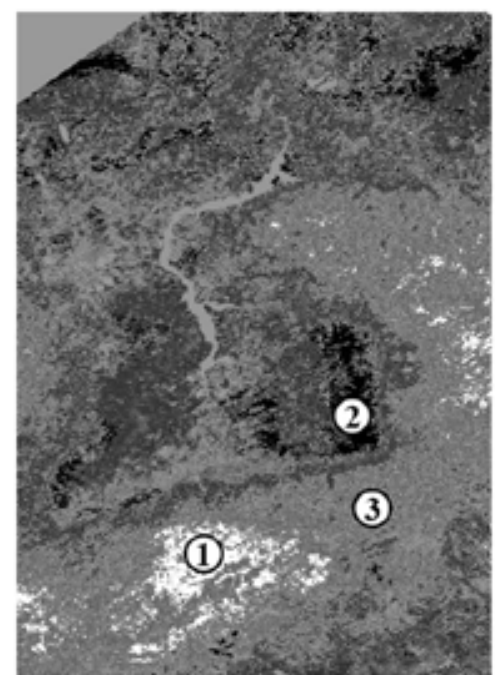

В. Карта типов растительности

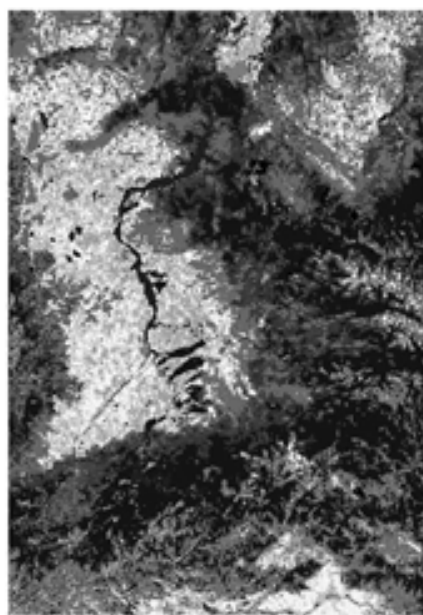

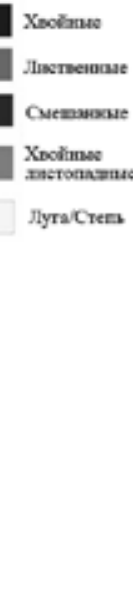

Рис. 2. А - пространственно распределенные нелинейные тренды ЧПП: 1 - пример зоны роста, 2 -пример зоны уменьшения, 3 - пример стабильной зоны значений трендов. В - карта типов растительности для изучаемой территории

имеют место только вырубки на ограниченных участках. Нужно отметить, что экосистемы на данных высотах более стабильны, здесь произрастают такие хвойные, как кедр и пихта, это одновозрастные леса горно-таежного пояса Западного Саяна. Именно на данных территориях происходил рост значений ЧПП за рассмотренный период времени, таким образом, по сравнению с 2000 г. здесь происходит увеличение депонирования углерода из атмосферы в процессе фотосинтеза.

C помощью метода STL возможно выделение не только общего тренда за длительный период времени, но и особенностей временной динамики ЧПП в различные годы внутри исследуемого периода времени. Например, на территории горных лесов в 2004 г. наблюдалось снижение значений ЧПП, в то время как на этой же территории наблюдается рост значений ЧПП в 2012 г. Таким образом, данный метод очень удобен для мониторинга динамики ЧПП, анализа причин наблюдаемой динамики и выделения внутренних закономерностей.

Для анализа причин появления аномалий в динамике ЧПП дополнительно рассматривались спутниковые данные по температуре и влажности. Чтобы генерализовать информацию для рассмотренной территории за двенадцать лет, в каждом пикселе были рассчитаны нелинейные временные тренды по данным температуры и влажности за 2000-2012 гг. по методу STL по аналогии с временными рядами значений ЧПП. Таким образом, для каждого пикселя изучаемой территории были получены нелинейные временные тренды по ЧПП, температуре и индексу влажности LSWI. Полученные карты с нелинейными временными трендами в каждом пикселе температуры и индекса влажности можно использовать для анализа динамических погодных тенденций на данной территории, которые зачастую являются причиной изменения в динамике ЧПП растительного покрова (табл. 1).

Для поиска возможных связей между значениями ЧПП и погодными характеристиками попиксельно был рассчитан коэффициент корреляции между парами рядов ЧПП - темпера- 

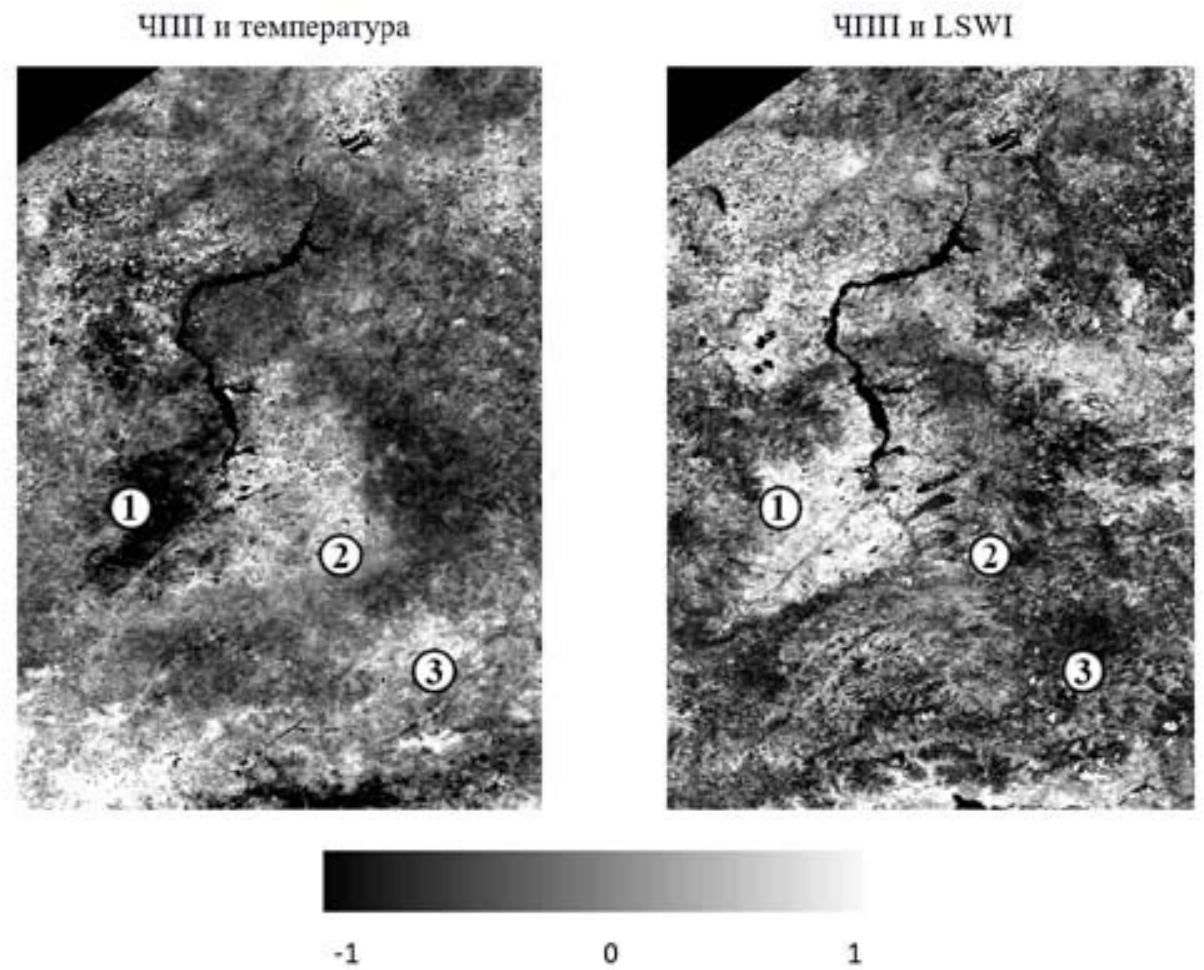

Рис. 3. Поля коэффициентов корреляции между парами рядов: ЧПП - температура; ЧПП - индекс влажности; 1, 2, 3 - пиксели с различными коэффициентами корреляции

тура и ЧПП - индекс влажности. Полученные в результате расчетов коэффициенты парной корреляции представлены на картах (рис. 3).

Одним из ключевых факторов, влияющим на значение ЧПП, является физиологическое состояние растительности. Любой внешний стресс, вызванный либо неблагоприятными погодными условиями (засуха, низкие температуры и др.), либо техногенным воздействием (кислотные дожди), за которым следует повреждение листовых пластинок/хвои и нарушение процессов фотосинтеза, приводит к уменьшению значений ЧПП [25]. Наряду с этим известно, что для каждого вида растений существует оптимальный интервал температуры и влажности, в котором процессы утилизации солнечной энергии проходят максимально эффективно [2]. Сдвиг от этого оптимума в любую сторону уменьшает значение ЧПП. Отражение этих закономерностей можно наблюдать на графиках на рис. 4. Пиксель под № 1 был выбран на территории степной зоны, где было выявлено наибольшее снижение значений ЧПП за рассмотренный период. В данном пикселе наблюдается большая отрицательная корреляция между нелинейными трендами ЧПП и температуры за рассмотренный период времени. Вместе с этим ряд ЧПП и ряд индекса влажности почвы LSWI связаны значительной положительной корреляцией. Можно сделать вывод о том, что в периоды роста температуры и вследствие этого снижения влаги в почве растения испытывают стресс от недостатка воды, вызванной продолжительными высокими температурами, и продуктивность в эти периоды времени снижается. Данные процессы очень типичны для растений степной и лесостепной зон, где лимитирующим жизнедеятель- 
ность фактором является именно наличие влаги в почве. Хочется отметить, что на данных территориях имеются и значительные по площади сельскохозяйственные угодья. В засушливые годы продуктивность на этих полях закономерно снижается и для получения высоких урожаев необходимо использование систем орошения.

Пиксель № 2 был выбран на территории смешанных лесов в предгорьях Саян. По своим экологическим особенностям (состав почв, флора и фауна) данные территории значительно отличаются от степной зоны, и поэтому мы наблюдаем на графиках табл. 1 другой характер влияния на ЧПП температуры и индекса влажности LSWI. Для этой территории температура не фактор стресса, наоборот, между динамикой ЧПП и температурой наблюдается положительная корреляция, повышение температуры на данных территория не вызывает водный стресс, а способствует росту растений. Влажность почвы перестает лимитировать рост и развитие растений, что отражается в малом коэффициенте корреляции между рядами ЧПП и индексом влажности LSWI.

Следующей рассмотренной территорией была территория хвойных высокогорных лесов (пиксель № 1 , рис. 3,4 ). Именно для этих растительных сообществ было получено увеличение значений ЧПП за рассмотренный период. Как показывает график и очень высокий коэффициент корреляции между рядами ЧПП и температурой (рис. 4, № 3), температура, бесспорно, является лимитирующим и регулирующим фактором для продуктивности растений на территории высотного пояса. С другой стороны, значительный отрицательный коэффициент корреляции между трендами индекса влажности и ЧПП отражают угнетающее влияние избытка влажности на жизнедеятельность растений рассмотренных горных экосистем.

После проведенного анализа влияния на динамику ЧПП значений рядов температуры и индекса влажности LSWI на территории юга Красноярского края можно отчетливо понять, что периоды высоких температур по-разному влияли на продуктивность растений в различных экологических условиях произрастания. Теплые годы вызвали снижение ЧПП растений, произраставших на территории степной и лесостепной зон, но это же увеличение температуры привело к росту значений ЧПП хвойных горных лесов. Таким образом, получают логичное экологическое объяснение расположение областей с аномальными значениями ЧПП и появление на рассмотренной территории юга Красноярского края зон роста, снижения и стабильных значений ЧПП (см. рис. 2).

\section{Выводы}

Предложенная технология обнаружения аномалий динамики чистой первичной продукции растительности позволяет определить зоны роста, уменьшения и стабильности значений ЧПП на обширной территории. Этот подход основан на экологической теории и дает возможность связать в единую концепцию не только динамику значений ЧПП, но и природные факторы (температура, влажность), напрямую влияющие на величину ЧПП. Данная концептуальная технология позволяет проводить мониторинг состояния экосистем на протяженной территории, используя оценки ЧПП (MODIS NPP) в качестве индикатора состояния растительного покрова.

Проведение расчетов с использованием метода STL на территории юга Красноярского края, обладающего большим разнообразием природных ландшафтов (от степей до высокогор-

$$
-121-
$$




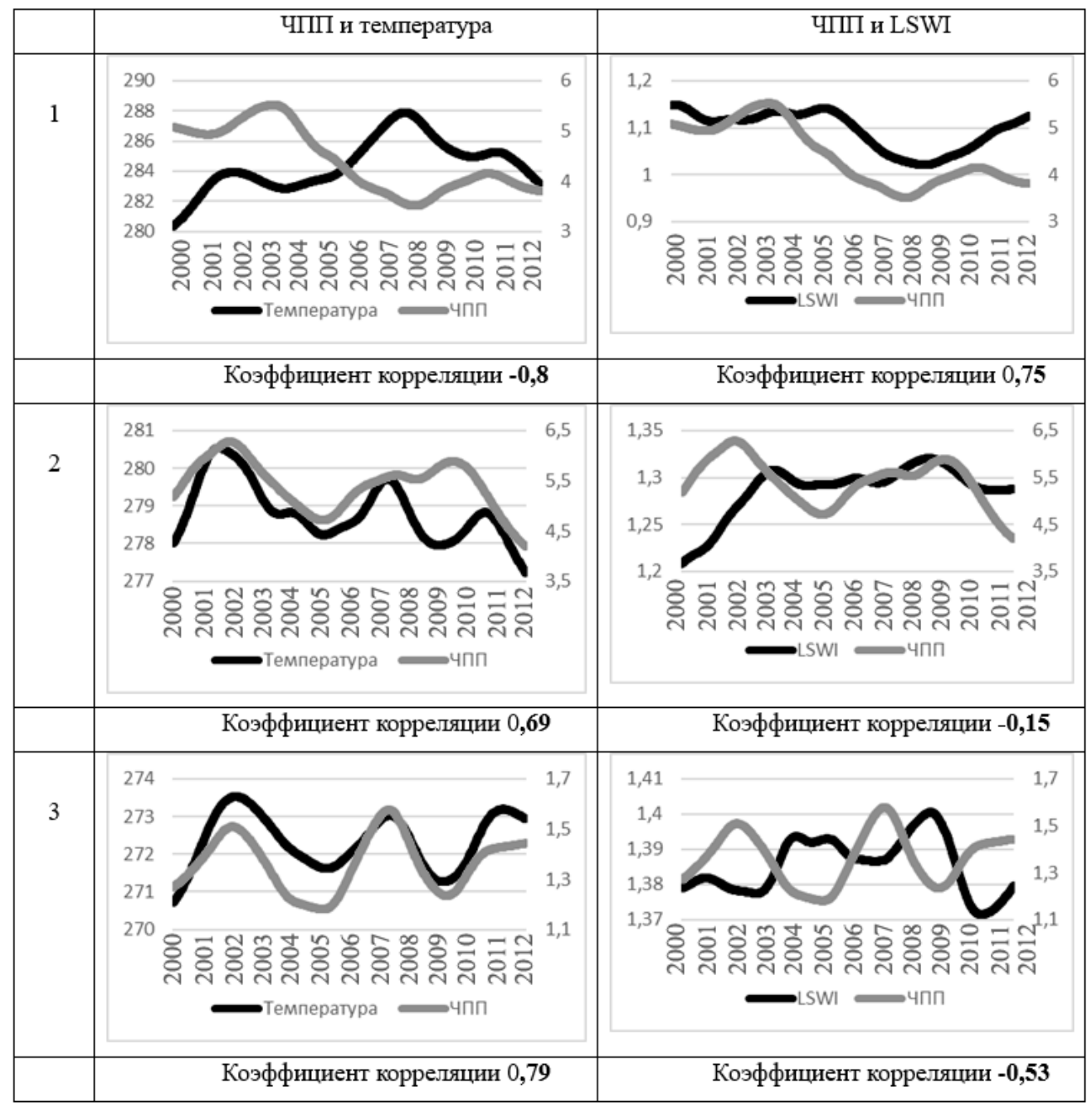

Рис. 4. Примеры нелинейных трендов ЧПП, температуры и индекса LSWI для пикселей с различным коэффициентом корреляции между рядами на рассмотренной территории

ных альпийских лугов), позволило оценить динамический отклик значений ЧПП различных растительных сообществ на близкие погодные режимы и выявить территориальные аномалии в динамике ЧПП. Пространственное распределение полученных нелинейных трендов выявило зоны уменьшения, роста и стабильного поведения ЧПП на исследуемой территории. Можно сделать вывод, что на большей части исследованной территории значения ЧПП остаются достаточно стабильными за 2000-2012 гг. Снижение значений ЧПП на данной территории произошло на равнинах и на территории предгорий Западного Саяна. Положительная динамика ЧПП за рассмотренный период времени наблюдается только на территории горных лесов Западного Саяна, занятой хвойными видами деревьев на высотах 600-1200 м над ур.м.

Наш подход определения территориальных аномалий ЧПП основан на показателях, которые просты и информативны для оценки состояния растительных сообществ. Они могут быть поняты широкой аудитории. Регулярный мониторинг этих показателей обеспечивает адекват- 
ную оценку состояния растительных сообществ и потенциально неблагоприятных изменений на обширных территориях.

Интеграция данных мониторинга растительного покрова на основе ЧПП с лесо- и землепользованием позволит прогнозировать потенциальное использование территорий с различными экологическими условиями и вырабатывать будущие сценарии рационального изменения растительного покрова с учетом экологических воздействий на основе анализа текущих тенденций и выявленных аномальных зон динамики ЧПП.

Работа поддержана грантами РФФИ и РГО в рамках научного проекта №̄ 17-0541012.

\section{Список литературы}

[1] Швиденко А.З., Щепащенко Д.Г. Углеродный бюджет лесов России. Сибирский лесной журнал, 2014, 1, 69-92. [Shvidenko A.Z., Schepaschenko D.G. The carbon budget of the Russian forests. Siberian forest journal, 2014, 1, 69-92. (in Russian)]

[2] Chapin F.S.III., Matson P.A., and Mooney H. A. Principles of Terrestrial Ecosystem Ecology. New York, Springer-Verlag, 2002, 398 p.

[3] Nilson T., Ross J. Modelling radiative transfer through forest canopies: implica tions for canopy photosynthesis and remote sensing, The Use of Remote Sensing in the Modelling of Forest Productivity, Dordrecht: Kluwer, 1997, 23-60 p.

[4] Martin M.E., Aber, J.D., Estimating forest canopy characteristics as inputs for models of forest carbon exchange by high spectral resolution remote sensing, The use of remote sensing in the modelling of forest productivity, Dordrecht: Kluwer, 1996, 61-72 p.

[5] Comins H.N., McMurtrie R.E., Long-term response of nutrient-limited forests to $\mathrm{CO}$ enrichment, equilibrium behavior of plant-soil models. Ecological Applications, 1993, 3, 666-681.

[6] Running, S.W., Coughlan, J.C. A general model of forest ecosystem processes for regional applications. I. Hydrologic balance, canopy gas exchange and primary production processes. Ecol. Model., 1988, 42, 125-154.

[7] Ollinger S.V., Aber, J.D. and Reich P.B. Simulating ozone eVects on forest productivity: interactions among leaf-, canopy-, and stand-level processes. Ecological Applications, 1997, 7, 1237-1251.

[8] Prince S.D., Goward S.M. Global primary production: a remote sensing approach. Journal of Biogeography, 1995, 22, 815-835.

[9] Hunt Jr, E.R., Piper S.C., Nemani R., Keeling C.D., Otto R.D., and Running S.W. Global net carbon exchange and intra-annual atmospheric $\mathrm{CO}$ concentrations predicted by an ecosystem process model and three-dimensional atmospheric transport model. Global Biogeochemical Cycles, 1996, 10, 431-456.

[10] Berner L.T., Beck P.S.A., Bunn A.G., Lloyd A.H., and Goetz S.J., High-latitude tree growth and satellite vegetation indices: Correlations and trends in Russia and Canada (1982-2008), J. Geophys. Res., 2011, 116.

[11] Lopatin E., Kolstrцm T. \& Spiecker H. Determination of forest growth trends in Komi Republic (northwestern Russia): combination of tree-ring analysis and remote sensing data. Boreal Env. Res., 2006, 11, 341-353. 
[12] Hilker T., Coops N.C., Wulder M.A., Black T.A., Guy R.D. The use of remote sensing in light use efficiency based models of gross primary production: A review of current status and future requirements. Science of the Total Environment, 2008, 404, 411-423.

[13] Сладких Л.А., Кулик Е.Н., Сахарова Е.Ю. Мониторинг посевов зерновых культур юга Западной Сибири по данным спутниковых наблюдений. Журнал Сибирского федерального университета. Техника \& Технологии, 2015, 6 (8), 726-733. [Sweet L.A., Kulik E.N., Sakharov E.Y. Monitoring of grain crops south of Western Siberia, according to satellite observations. J. Sib. Fed. Univ. Eng. Technol., 2015, 6 (8), 726-733. (in Russian)]

[14] Федотова Е.В., Жолудев А.А., Изосимов В.Г., Шпирук Ю.Д., Маглинец Ю.А., Цибульский Г.М. Анализ сезонной динамики растительного покрова на основе данных дистанционного зондирования Земли. Журнал Сибирского федерального университета. Техника \& Технологии, 2014, 8(7), 976-983.[Fedotova E.V., Zholudev A.A., Izosimov V.G., Shpiruk Y.D., Maglinets Y.A., Cybulski G.M. The analysis of seasonal dynamics of vegetation based on remote sensing data. J. Sib. Fed. Univ. Eng. Technol., 2015, 6 (8), 726-733. (in Russian)]

[15] Чулочникова О.В., Бойко С.М., Степанов В.С., Кайнова А., Цицвера Н., Головко Т. Природа Ермаковского района. Абакан: Фирма Март, 2005, 61 с. [Chulochnikova O.V., Boiko S.M., Stepanov V.S., Kaynova A. Tsitsvera N. Golovko T. Nature Ermakovskogo area. Abakan, The company in March, 2005, 61 p. (in Russian)]

[16] Hüttich C., Herold M., Schmullius C., Egorov V. and Bartalev S.A. SPOT-VGT NDVI and NDWI trends 1998-2005 as indicators of recent land cover change processes in northern Eurasia. Proceedings of the 2nd Workshop of the EARSeL SIG on Land Use and Land Cover, 2006, 336-344.

[17] Heinsch F.A., Zhao M., Running S.W., Kimball J.S., Nemani R.R., Davis K.J., Bolstad P.V., Cook B.D., Desai A.R., Ricciuto D.M. Evaluation of remote sensing based terrestrial productivity from MODIS using regional tower eddy flux network observations. IEEE Transactions on Geoscience and Remote Sensing 2006, 44, 1908-1923.

[18] Soja A.J., Tchebakova N.M., French Nancy H.F., Flannigan M.D., Shugart H.H., Stocks B.J., Sukhinin A.I., Parfenova E.I., F. Chapin F.S.III., Stackhouse, W.Jr. Climate-induced boreal forest change: Predictions versus current observations. Global and Planetary Change, 2007, 56, 274-296.

[19] Potter C, Klooster S, Myneni R, Genovese V, Tan PN, Kumar V Continental-scale comparisons of terrestrial carbon sinks estimated from satellite data and ecosystem modeling 1982--1998. Global and Planetary Change 2003, 39, 201-213.

[20] Cao M, Prince S.D., Small J, Goetz S.J. Remotely sensed interannual variations and trends in terrestrial net primary productivity 1981-2000. Ecosystems, 2004, 7, 233-242.

[21] Zhao M, Heinsch F.A., Nemani R.R., Running S.W. Improvements of the MODIS terrestrial gross and net primary production global data set. Remote Sensing of Environment, 2005, 95, 164-176.

[22] Zhao M., Running S.W. Drought-Induced Reduction in Global Terrestrial Net Primary Production from 2000 Through 2009. Science, 2010, 329(5994), 940-943.

[23] Cleveland R. B., Cleveland W. S., McRae J.E., and Terpenning I. STL: A Seasonal-Trend Decomposition Procedure Based on Loess. Journal of Official Statistics, 1990, 6, 3-73

[24] Ларько А.А., Иванова Ю.Д., Шевырногов А.П. Нелинейные тренды чистой первичной продукции растительности юга Красноярского края по спутниковым данным: методы и подходы. Фундаментальные исследования, 2015, 3(0). 106-110. [Larko A.A., Ivanov Y.D., Shevyrnogov 
A.P. Nonlinear trends in net primary production of vegetation south of the Krasnoyarsk Territory from satellite data: methods and approaches. Fundamental Research, 2015, 3 (0). 106-110. (in Russian)]

[25] Суховольский В.Г., Иванова Ю.Д. Рост лесных насаждений как аналог процесса производства в экономических системах: Е2Е модель. Сибирский лесной журнал, 2015, 1, 22-33. [Soukhovolsky V.G., Ivanov Y.D. The growth of forest plantations as an analogue of the production process in economic systems: E2E model. Siberian forest journal, 2015, 1, 22-33. (in Russian)] 